\title{
Kemampuan Representasi Matematis Melalui Pembelajaran Berbasis Masalah Berbantuan Software Wolfram Mathematica
}

\author{
Yoni Sunaryo \\ Prodi Pendidikan Matematika, Universitas Galuh, Ciamis, Indonesia; \\ sunaryoyoni@gmail.com
}

Info Artikel: Dikirim: 18 Oktober 2019; Direvisi: 31 Januari 2020; Diterima: 4 Maret 2020 Cara sitasi: Sunaryo, Y. (2020). Kemampuan Representasi Matematis Melalui Pembelajaran Berbasis Masalah Berbantuan Software Wolfram Mathematica. JNPM (Jurnal Nasional Pendidikan Matematika), 4(1), 85-95.

\begin{abstract}
Abstrak. Penelitian ini memiliki tujuan untuk mengetahui peningkatan kemampuan representasi matematis mahasiswa melalui model pembelajaran berbasis masalah dengan bantuan software wolfram mathematica. Metode penelitian ini adalah kuasi eksperimen. Populasi penelitian ini adalah seluruh mahasiswa pendidikan matematika semester enam Universitas Galuh. Pengambilan sampel penelitian menggunakan cara cluster random sampling. Sebanyak 50 mahasiswa terpilih, yang dikelompokan menjadi satu kelas sebagai kelas eksperimen dan satu kelas sebagai kelas kontrol. Instrumen penelitian ini adalah soal tes kemampuan representasi matematis pada mata kuliah Pemograman Linier. Hasil penelitian menunjukan bahwa peningkatan kemampuan representasi matematis mahasiswa yang belajar menggunakan model pembelajaran berbasis masalah berbantuan software wolfram mathematica lebih baik daripada yang belajar menggunakan pembelajaran konvensional. Kemampuan mahasiswa dalam mengoperasikan software wolfram mathematica menjadi kunci agar semua mahasiswa dapat penyelesaian soal pemograman linear.
\end{abstract}

Kata Kunci: Pembelajaran Berbasis Masalah, Software Wolfram Mathematica, Representasi Matematis.

\begin{abstract}
The purpose of this study was to determine the improvement of students' mathematical representation abilities through problem-based learning models assisted by Wolfram Mathematica software. This research was quasi-experimental. The population was all sixth-semester mathematics education students at Galuh University. Sampling was taken by random cluster sampling. A total of 50 students were selected, grouped into one class as an experimental class and one class as a control class. This research instrument was tests of mathematical representation ability in the Linear Program subject. The results showed that the increase of mathematical representation ability of students who learned by problem-based learning models assisted by Wolfram Mathematica Software was better than students who learned by Conventional Learning. The ability of students to operate the Wolfram Mathematica Software was a key so that all students could solve linear program problems.
\end{abstract}


Keywords: Problem Based Learning, Wolfram Mathematica Software, Mathematical Representation.

\section{Pendahuluan}

Matematika merupakan ilmu universal yang mendasari perkembangan teknologi modern. Selain itu, matematika juga membantu mengembangkan kemampuan berpikir manusia. Matematika adalah ratu dari ilmu pengetahuan karena konsep matematika dapat dikembangkan secara mandiri tanpa peran ilmu lain dan matematika adalah pelayan pengetahuan, karena matematika diperlukan oleh semua ilmu pengetahuan (Suyitno, 2016). Kemampuan berpikir matematis dibagi menjadi tiga kategori sesuai dengan tingkatan berpikirnya yaitu Higher Order Thinking Skills (HOTS), Medium Order Thinking Skills (MOTS) dan Low Order Thinking Skills (LOTS). HOTS merupakan kemampuan yang wajib dimiliki mahasiswa agar kelak mampu berkompetisi di dunia kerja. Kemampuan representasi matematis termasuk kemampuan berpikir tingkat tinggi.

Kemampuan representasi matematis adalah kemampuan untuk dapat menyajikan kembali konsep matematika ke dalam bentuk lain. Oleh sebab itu kemampuan ini sangat penting untuk dimiliki oleh mahasiswa dalam memahami konsep matematis berupa gambar, simbol, dan kata-kata tertulis. Guru sebaiknya mendorong siswa untuk mengembangkan kemampuan representasi matematisnya selama melakukan pembelajaran di kelas (Sabirin, 2014). Penggunaan representasi yang tepat akan membantu mahasiswa menjadikan ide-ide matematis lebih konkrit. Penggunaan representasi yang sesuai dengan permasalahan dapat membuat permasalahan yang rumit menjadi lebih sederhana, sebaliknya konstruksi representasi yang keliru akan membuat masalah menjadi sulit untuk dipecahkan. Konfigurasi dari pemikiran seseorang secara keseluruhan atau terbagi-bagi yang terhubung satu dengan lain secara simultan (Goldin \& Kaput, 2015).

Salah satu mata kuliah yang berkaitan erat dengan representasi matematis adalah mata kuliah pemograman linier. Kenyataan yang ada di lapangan berdasarkan hasil nilai ujian akhir semester mata kuliah tersebut menunjukkan rata-rata nilai mahasiswa yang mengikuti perkuliahan Pemrograman Linear adalah sebanyak 64\% memperoleh nilai dibawah 75. Kesulitan yang dialami mahasiswa adalah pada penyajian grafik penyelesaian dan pembuatan formula pertidaksamaan dari perosalan yang ada. Hal ini menunjukkan adanya kesulitan belajar yang dialami mahasiswa. 
Kesulitan belajar matematika ternyata tidak hanya dialami siswa yang duduk di bangku sekolah (Özerem, 2012), melainkan juga mahasiswa yang sudah duduk di bangku kuliah serta hampir pada setiap jenjang pendidikan siswa mengalami kesulitan dalam belajar matematika. Bahkan orang dewasa pun mengalami kesulitan ini (Kereh, Sabandar \& Tjiang, $\underline{2013})$.

Kesulitan mahasiswa pada saat melakukan representasi matematis adalah adanya keterbatasan mereka dalam mengendalikan representasi, dan relasi antar model, serta penggunaan bahasa yang tepat untuk merepresentasikan dan memanipulasi konsep matematika (Sinclair, Bussi, de Villiers, Jones, Kortenkamp, Leung, \& Owens, 2016). Hasil penelitian menunjukan bahwa mahasiswa matematika di Inggris kurang mampu memilih modus representasi yang tepat karena mereka kurang komunikatif dalam mengekspresikan pikirannya (Fonna, 2018). Pada umumnya siswa di Indonesia mengalami kesulitan untuk menyelesaikan masalah non rutin yang mencapai tahap analisis, sehingga dapat disimpulkan bahwa kemampuan siswa di Indonesia dalam representasi matematis masih rendah (Noer, Gunowibowo, \& Pentatito, 2018).

Kemampuan mahasiswa dalam melakukan representasi matematis dapat dilatih dan dikembangkan. Upaya yang dapat dilakukan agar dapat meningkatnya kemampuan representasi matematis mahasiswa adalah dengan menggunakan model pembelajaran yang mendukung terhadap hal tersebut karena selama ini pembelajaran yang dilaksanakan berfokus pada hal-hal prosedural dan mekanistik, teacher centered dan penyampaian konsep matematika secara informatif (Herman, 2007).

Terdapat model pembelajaran yang mendukung terhadap peningkatan kemampuan representasi matematik mahasiswa yaitu model Pembelajaran Berbasis Masalah/Problem-Based Learning (PBL). Langkah-langkah PBL yang khas, dimana pembelajaran dipicu oleh masalah yang membutuhkan resolusi. Studi tentang efektivitas PBL secara umum menunjukkan bahwa siswa yang telah mengalami PBL mencapai hasil belajar tinggi dibandingkan dengan siswa dalam lingkungan belajar berbasis kuliah (Yew \& Goh, 2016).

Pembelajaran berbasis masalah menghadapkan siswa pada situasi atau masalah yang menuntun siswa melakukan proses doing math secara aktif sehingga dapat lebih mengenal objek matematika dan dapat menginterpretasikan kembali ide matematika dalam membentuk pemahaman baru (Sari \& Rahadi, 2014). 
Kemajuan teknologi penting untuk diikuti dan dimanfaatkan terutama saat melaksanakan pembelajaran agar mahasiswa menguasainya. Nugraha (2017) menyatakan bahwa dewasa ini telah banyak software yang bisa digunakan untuk membuat dan merancang suatu program komputer yang bisa dibuat interaktif ditambah dengan fasilitas multimedia yang lengkap, seperti suara, gambar, animasi, teks, dan video. Menggunakan multimedia adalah suatu keharusan untuk meningkatkan tingkat motivasi siswa (Uygarer \& Uzunboylu, 2017).

Penggunaan software wolfram mathematica sebagai alat bantu proses pembelajaran dalam PBL masih jarang dilakukan. Software ini sangat mendukung untuk membuat grafik penyelesaian dari persoalan pemograman linier dan dapat mencari nilai optimum dengan cara menginput pertidaksamaan-pertidaksamaannya ke dalam area. Sehingga Software ini dapat digunakan pada mata kuliah pemograman Linier pada topik menyelesaikan persoalan linear programming dengan metode grafik. Oleh sebab itu tujuan penelitian ini adalah untuk mengetahui peningkatan kemampuan representasi matematis mahasiswa dengan model pembelajaran berbasis masalah berbantuan software wolfram mathematica.

\section{Metode}

Jenis penelitian ini adalah kuasi eksperimen dimana pengambilan sampel tidak benar-benar diacak akan tetapi pengacakan terjadi pada kelas yang termasuk pada populasi penelitian. Pengambilan sampel penelitian dilakukan secara cluster random sampling yakni acak kelas dengan mengambil satu kelas sebagai kelas eksperimen yang terdiri dari 17 orang mahasiswa dan satu kelas sebagai kelas control yang terdiri dari 23 orang mahasiswa. Cluster random sampling dilakukan karena populasi penelitian memiliki karakteristik yang relatif sama/homogen. Kelas eksperimen adalah kelas yang belajar dengan menggunakan model pembelajaran berbasis masalah dengan bantuan software wolfram mathematica, sedangkan kelas kontrol adalah kelas yang belajar dengan menggunakan Pembelajaran Konvensional yaitu dengan model pembelajaran langsung.

Desain penelitian pada penelitian ini adalah posttest only control group design. Populasi penelitian ini adalah seluruh mahasiswa matematika semester enam Universitas Galuh yang terdiri dari tiga kelas. Instrumen penelitian ini adalah soal tes kemampuan representasi matematis pada mata kuliah pemograman linier. Soal tersebut terlebih dahulu diujicobakan untuk melihat validitas, reliabilitas, daya pembeda dan indeks kesukaran sehingga 
diperoleh soal yang layak. Data yang diolah adalah data gain ternormalisasi yang diperoleh dari skor pretes dan postes mahasiswa. Data gain ternormalisasi kemudian dianalisis menggunakan statistik inferensial dengan langkah pertama yaitu melakukan uji normalitas, uji homogenitas, dan uji t.

\section{Hasil dan Pembahasan}

Pengolahan data pada nilai gain ternormalisasi menggunakan software SPSS yang diawali dengan uji normalitas. Uji normalitas dilakukan dengan tujuan untuk melihat data gain ternormalisasi yang diperoleh berasal dari populasi berdistribusi normal atau tidak. Uji yang digunakan pada uji normalitas adalah uji Shapiro-Wilk dikarenakan datanya termasuk data kecil yaitu $\leq 30$. Pengujian normalitas data dengan taraf signifikansi atau $\alpha=5 \%$. Hasil dari uji normalitas disajikan pada Tabel 1.

Tabel 1. Hasil Uji Normalitas

\begin{tabular}{cccccc}
\hline Uji & Kelas & $\mathrm{N}$ & Sig. & $\mathrm{H}_{0}$ & Keterangan \\
\hline $\begin{array}{c}\text { Shapiro- } \\
\text { Wilk }\end{array}$ & PBL & 17 & 0,08 & Terima & Berdistribusi normal \\
\hline
\end{tabular}

Hasil perhitungan pada Tabel 1 menunjukkan bahwa nilai signifikansi kedua kelas lebih besar dari 0,05. Dengan demikian $\mathrm{H}_{0}$ diterima atau $\mathrm{H}_{1}$ ditolak. Oleh karena itu disimpulkan bahwa kedua kelas tersebut berdistribusi normal.

Setelah diketahui data berasal dari populasi yang berdistribusi normal maka selanjutnya melakukan uji homogenitas varians untuk mengetahui data gain ternormalisasi kelas eksperimen dan kelas kontrol memiliki varians yang homogen atau tidak. Pengujian homogenitas menggunakan uji Levene's Test for Equality of Variances yang merupakan prasyarat untuk melakukan uji $\mathrm{t}$ dengan nilai signifikansi atau $\alpha=5 \%$. Hasil dari uji homogentias disajikan pada Tabel 2.

Tabel 2. Hasil Uji Homogenitas

\begin{tabular}{cccc}
\hline Uji & Sig. & $\mathrm{H}_{0}$ & Keterangan \\
\hline Levene's Test & 0,73 & Terima & Homogen \\
\hline
\end{tabular}

Hasil perhitungan pada Tabel 2 menunjukkan bahwa nilai signifikansi lebih besar dari 0,05. Dengan demikian $\mathrm{H}_{0}$ diterima atau $\mathrm{H}_{1}$ ditolak. Oleh karena itu disimpulkan bahwa varians kelas eksperimen dan kelas kontrol homogen. 
Asumsi untuk melakukan uji $\mathrm{t}$ terpenuhi yaitu data gain ternormalisasi berdistribusi normal dan homogen maka tahap selanjutnya adalah melakukan uji t untuk menguji hipotesis. Nilai signifikansi atau $\alpha$ yang digunakan adalah 5\%. Berikut hipotesis statistika uji $t$ untuk menguji perbedaan rata-rata gain ternormalisasi.

$\mathrm{H}_{0}: \mu_{x} \leq \mu_{y}$

$\mathrm{H}_{1}: \mu_{x}>\mu_{y}$

Keterangan :

$\mu_{x}=$ Parameter rerata gain ternormalisasi kelompok eksperimen

$\mu_{y}=$ Parameter rerata gain ternormalisasi kelompok kontrol

Hipotesis yang diajukan:

$\mathrm{H}_{0}$ : Peningkatan kemampuan representasi matematis mahasiswa yang menggunakan model pembelajaran berbasis masalah berbantuan software wolfram mathematica tidak lebih baik daripada mahasiswa yang memperoleh Pembelajaran Konvensional

$\mathrm{H}_{1}$ : Peningkatan kemampuan representasi matematis mahasiswa yang menggunakan model pembelajaran berbasis masalah berbantuan software wolfram mathematica lebih baik daripada mahasiswa yang memperoleh Pembelajaran Konvensional

Hasil analisis data gain ternormalisasi menggunakan uji $\mathrm{t}$ disajikan pada Tabel 3.

Tabel 3. Hasil Uji Pasangan Hipotesis
\begin{tabular}{ccc}
\hline Uji & Sig. & $\mathrm{H}_{0}$ \\
\hline$t$ & 0,01 & Tolak \\
\hline
\end{tabular}

Tabel 3 menunjukan bahwa nilai signifikansi sebesar 0,01 yang berarti kurang dari 0,05. Dengan demikian $\mathrm{H}_{0}$ ditolak. Oleh karena itu disimpulkan bahwa peningkatan kemampuan mahasiswa dalam representasi matematis yang menggunakan model pembelajaran berbasis masalah dengan bantuan software wolfram mathematica lebih baik daripada yang memperoleh pembelajaran konvensional.

Hasil yang diperoleh dari penelitian ini adalah dampak dari perbedaan pembelajaran yang dilaksanakan di kelas yang menjadi sampel penelitian. Pembelajaran di kelas eksperimen menerapkan model pembelajaran Berbasis Masalah menggunakan software wolfram mathematica. Pada pelaksanaan 
pembelajarannya, mahasiswa berdiskusi untuk menyelesaikan masalah yang ada pada LKS secara berkelompok. Diskusi yang dilaksanakan membuat mahasiswa dapat menuangkan gagasan-gagasan mereka agar masalah yang dihadapi dapat diselesaikan. Pengajuan ide-ide tersebut dapat membantu mahasiswa yang berkemampuan akademik rendah menjadi terbantu oleh mahasiswa yang berkemampuan akademik tinggi dan sedang dalam memahami materi. Guru harus dapat mendorong siswa untuk berdiskusi (Pijls \& Dekker, 2011).

Pada proses pembelajarannya mahasiswa belajar secara mandiri karena pembelajaran berpusat pada mahasiswa. Bantuan yang diberikan oleh dosen tidak hanya berupa bimbingan dalam menyelesaikan masalah. Masalah yang diberikan merupakan masalah kontekstual dan tidak rutin. Maksudnya adalah masalah yang tingkat kesulitannya melebihi soal-soal yang biasa diberikan. Karakteristik utama dari lingkungan pembelajaran PBL adalah berfokus pada masalah yang memiliki hubungan timbal balik antara pengetahuan dan masalah, berpusat pada siswa dan mandiri yang artinya siswa secara individu dan kolaboratif memikul tanggung jawab untuk menyelesaikan masalah (Marra, Jonassen, Palmer, \& Luft, 2014).

Pembelajaran berbasis masalah merupakan pembelajaran yang menuntut keaktifan mahasiswa dalam menggali pengetahuannya sendiri. Problem based Learning merupakan salah satu cara untuk menciptakan pembelajaran yang aktif (Rahmawati, Riyadi, \& Subanti, 2015). Sebuah masalah yang dianggap rumit dan kompleks dapat menjadi lebih sederhana jika menggunakan strategi dan pemanfaatan representasi matematika yang sesuai dengan permasalahan tersebut (Kholiqowati, Sugiarto, \& Hidayah, 2016). Esensi dari tahap pembelajaran ini adalah mengeksplorasi untuk memecahkan masalah agar dapat menciptakan, menggabungkan dan menggeneralisasi pengetahuan melalui kegiatan yang berpusat pada siswa saat menggabungkan pengetahuan baru dan pengetahuan yang telah dimiliki (Kemendikbud, 2013). Model pembelajaran Problem Besed Learning sering disebut dengan metode eksperimen, metode reflektif, dan metode ilmiah (Ayuningsih, Kristin, \& Anugrahen, 2019).

Penggunaan software wolfram mathematica juga memiliki dampak positif pada peningkatan kemampuan mahasiswa dalam representasi matematis karena software ini dapat menampilkan visualisasi berupa gambar atau grafik dari suatu sistem pertidaksamaan linear yang hendak diselesaikan mahasiswa. Terdapat masalah pada pengajaran representasi matematika dasar yaitu guru gagal untuk mementingkan representasi matematika (Zhe, 2012). 
Kualitas pengajaran representasi matematis dipengaruhi oleh banyak faktor tidak memuaskan. Pengajaran bahasa matematika harus diperkuat. Oleh karena itu, penting bagi guru untuk mempertimbangkan jenis bantuan dan umpan balik yang efektif bagi siswa (Inventado, Scupelli, Ostrow, Heffernan, Ocumpaugh, Almeda, \& Slater, 2018). Selain sebagai bantuan dalam visualisasi grafik, penggunaan software ini juga membuat mahasiswa dapat mengetahui jawaban dari soal yang telah mereka selesaikan secara manual apakah sudah tepat atau belum. Tampilan dari salah satu soal yang diselesaikan oleh software ini ditampilkan pada Gambar 1

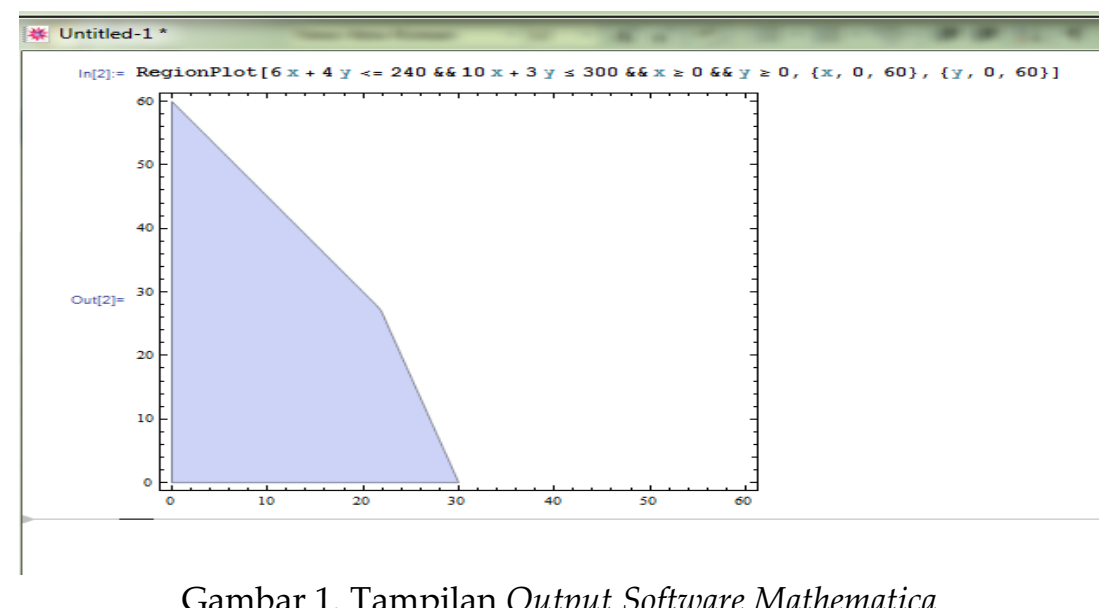

Gambar 1. Tampilan Output Software Mathematica

Gambar 1 menunjukkan area yang menjadi daerah penyelesaian dari soal pertidaksamaan linear. Output ini dihasilkan dari menginput pertidaksamaan-pertidaksamaan ke dalam software sehingga diperoleh visualisasi grafiknya. Representasi masalah matematika sebagai strategi adalah praktik berbasis bukti (Jitendra \& Anand, 2016). Software Mathematica mampu mengkombinasikan manipulasi simbolik, matematika numerik, bahasa pemrograman yang canggih dan luar biasa tampilan grafiknya (Baist, Firmansyah, \& Pamungkas, 2019).

Hasil penelitian ini juga sejalan dengan penelitian yang dilakukan oleh Nugraha (2017) yang menunjukkan bahwa terdapat perbedaan yang signifikan antara peningkatan kemampuan representasi multipel matematis siswa yang memperoleh pembelajaran secara keseluruhan. Utami, Santi, \& Suparman (2018) juga melakukan penelitian dengan hasil penelitian bahwa model pembelajaran PBL memberi pengaruh terhadap hasil belajar kognitif peserta didik. Selain itu, Sundawan \& Nopriana (2019) menjelaskan bahwa model pembelajaran ini juga dinilai berhasil dalam mengembangkan kemampuan representasi matematis. 


\section{Simpulan}

Hasil dari analitis data diperoleh simpulan bahwa mahasiswa yang menggunakan model pembelajaran berbasis masalah berbantuan software wolfram mathematica memiliki peningkatan kemampuan representasi matematis yang lebih baik dari yang menggunakan Pembelajaran Konvensional. Rekomendasi dari penelitian ini adalah sebaiknya pada saat melakukan pembelajaran dicek satu persatu kemampuan mahasiswa dalam mengoperasikan software tersebut agar semua mahasiswa menguasai langkah-langkah penyelesaian soal pemograman linier dengan software wolfram mathematica.

\section{Ucapan Terima Kasih}

Ucapan terimakasih ditujukan kepada Prodi Pendidikan Matematika Universitas Galuh Ciamis yang telah mendukung dari segi moril sehingga penelitian ini dapat terlaksana dan mahasiswa yang telah menjadi sampel penelitian ini.

\section{Daftar Pustaka}

Ayuningsih, D., Kristin, F., \& Anugraheni, I. (2019). Penerapan Model Pembelajaran Problem Based Learning (PBL) untuk Meningkatkan Hasil Belajar dan Berpikir Kritis Matematika. Jurnal Cakrawala Pendas 5(2), 94-99.

Baist, A., Firmansyah, M. A., \& Pamungkas, A.S. (2019). Desain Bahan Ajar Komputasi Matematika Berbantuan Software Mathematica Untuk Mengembangkan Kemandirian Belajar Mahasiswa. Jurnal Fibonacci. 5(1), 29-36.

Fonna, M., \& Mursalin, M. (2018). Role of Self-Efficacy Toward Students' Achievement in Mathematical Multiple Representation Ability (MMRA). Jurnal Ilmiah Peuradeun 6(1), 31-40.

Goldin, G.A., \& Kaput, J.J. (2015). A Joint Perspective on The Idea of Representation in Learning and Doing Mathematics. ResearchGate.

Herman, T. (2007). Pembelajaran Berbasis Masalah untuk Meningkatkan Kemampuan Penalaran Matematis Siswa SMP. Cakrawala Pendidikan, 1(1), 41-62.

Inventado, P. S., Scupelli, P., Ostrow, K., Heffernan, N., Ocumpaugh, J., Almeda, V. \& Slater, S. (2018). Contextual factors affecting hint utility. International Journal of STEM Education 5(13). 1-13.

Jitendra, P., \& Anand, V. K. (2016). Eight new records of fresh water filamentous algae (Oedogonium Link) from India. Tropical Plant Research, 3(1), 33-39.

Kereh, C. T., Sabadar, J., \& Tjiang, P. C. (2013). Identifikasi kesulitan belajar mahasiswa dalam konten matematika pada materi pendahuluan fisika inti. Proceedings of Seminar Nasional Sains dan Pendidikan Sains VIII, 4(1), 10-17.

Kemendikbud. (2013). Modul Pelatihan Kurikulum 2013. Jakarta: Badan Pengembangan Sumber Daya Manusia Pendidikan dan Kebudayaan dan Penjaminan Mutu Pendidikan, Kemendikbud.

Kholiqowati, H., Sugiarto., \& Hidayah, I. (2016). Analisis Kemampuan Representasi Matematis Ditinjau dari Karakteristik Cara Berpikir Peserta Didik dalam Pembelajaran dengan Pendekatan Saintifik. Journal of Mathematics Education. 5(3). 234242. 
Marra, R. M., Jonassen, D. H., Palmer, B., \& Luft, S. (2014). Why Problem-Based Learning Works: Theoretical Foundations. Journal on Excellence in College Teaching, 25(3\&4), 221238.

Noer, S. H., Gunowibowo, P \& Pentatito. (2018). Efektivitas Problem Based Learning Ditinjau Dari Kemampuan Berpikir Kritis dan Representasi JPPM (Jurnal Penelitian dan Pembelajaran Matematika), 11(2), 17-32.

Nugraha, D. A. (2017). Penerapan Pembelajaran Berbasis Masalah Berbantuan Program Geometer's Sketchpad untuk Meningkatkan Kemampuan Representasi Multipel Matematis Siswa. Jurnal Teorema : Teori dan Riset Matematika, 1(2), 1-10.

Özerem, A. (2012). Misconceptions in Geometry and Suggested Solutions for Seventh Grade Students. International Journal of New Trends in Arts, Sports \& Science Education, 1(4), 23-35.

Pijls, M., \& Dekker, R. (2011). Students Discussing Their Mathematical Ideas: The Role of The Teacher. Mathematics Education Research Journal 23(4). 379-396.

Rahmawati, A.D., Riyadi, \& Subanti, S (2015). Analisis Proses Pembelajaran Berbasis Masalah (Problem Based Learning) Matematika Dengan Pendekatan Ilmiah (Scientific Approach ) Di Sma Negeri 1 Jogorogo Kelas X Kabupaten Ngawi Tahun Pelajaran 2013/2014. Jurnal Elektronik Pembelajaran Matematika, 3(10). 1099-1109.

Sabirin, M. (2014). Representasi dalam Pembelajaran Matematika. JPM IAIN Antasari. 1(2), 33-44.

Sari, L. S. P \& Rahadi, M. (2014). Pembelajaran Berbasis Masalah untuk Meningkatkan Kemampuan Komunikasi Matematika Siswa. Jurnal Pendidikan Matematika. 3(3), 143150.

Sinclair, N., Bussi, M. G. B., de Villiers, M., Jones, K., Kortenkamp, U., Leung, A., \& Owens, K. (2016). Recent Research on Geometry Education: An ICME-13 Survey Team Report. ZDM, 48(5), 691-719.

Sundawan, M. D., \& Nopriana, T. (2019). Guided-Discovery Learning, Representasi Matematis dan Konsep Diri Mahasiswa pada Materi Geometri. JNPM (Jurnal Nasional Pendidikan Matematika), 3(1), 123-134.

Suyitno, H. (2016). Pengantar Filsafat Matematika, Yogyakarta: Magnum Pustaka Utama.

Utami, T. S., Santi, D \& Suparman, A. R. (2018). Pengaruh Model Pembelajaran Problem Based Learning (PBL) Terhadap Hasil Belajar Kognitif Peserta Didik Kelas Xi Smk Negeri 02 Manokwari (Studi Pada Materi Pokok Konsep Laju Reaksi). Arfak Chem Chemistry Education Journal 1(1), 21-26.

Uygarer, R., \& Uzunboylu, H. (2017). An investigation of the digital teaching book compared to traditional books in distance education of teacher education programs. Eurasia Journal of Mathematics, Science and Technology Education 13(8), 5365-5377.

Yew \& Goh. (2016). Problem-Based Learning: An Overview of its Process and Impact on Learning. International Journal of Helath Profession Education 1(2), 75-79.

Zhe, L. (2012) . Survey of Primary Students' Mathematical Representation Status and Study on the Teaching Model of Mathematical Representation. Journal of Mathematics Education 5(1), 63-76. 